University of Nebraska - Lincoln

DigitalCommons@University of Nebraska - Lincoln

Publications from USDA-ARS / UNL Faculty

U.S. Department of Agriculture: Agricultural

Research Service, Lincoln, Nebraska

2006

\title{
Human Emanations and Related Natural Compounds That Inhibit Mosquito Host-Finding Abilities
}

Ulrich R. Bernier

University of Florida, ubernier@gainesville.usda.ufl.edu

Daniel Kline

United States Department of Agriculture-ARS-Center for Medical

Kenneth H. Posey

United States Department of Agriculture-ARS-Center for Medical

Follow this and additional works at: https://digitalcommons.unl.edu/usdaarsfacpub

Part of the Agricultural Science Commons

Bernier, Ulrich R.; Kline, Daniel; and Posey, Kenneth H., "Human Emanations and Related Natural Compounds That Inhibit Mosquito Host-Finding Abilities" (2006). Publications from USDA-ARS / UNL Faculty. 948.

https://digitalcommons.unl.edu/usdaarsfacpub/948

This Article is brought to you for free and open access by the U.S. Department of Agriculture: Agricultural Research Service, Lincoln, Nebraska at DigitalCommons@University of Nebraska - Lincoln. It has been accepted for inclusion in Publications from USDA-ARS / UNL Faculty by an authorized administrator of DigitalCommons@University of Nebraska - Lincoln. 


\title{
Human Emanations and Related Natural Compounds That Inhibit Mosquito Host-Finding Abilities
}

\author{
Ulrich R. Bernier, Daniel L. Kline, and Kenneth H. Posey
}

\section{CONTENTS}

Concepts and Terminology Used in This Chapter ................................................................ 78

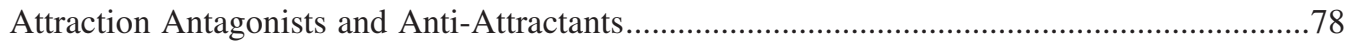

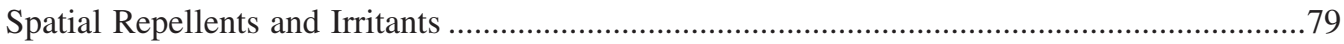

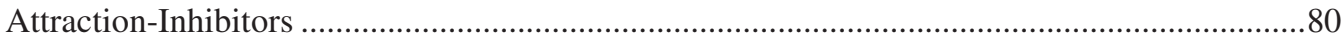

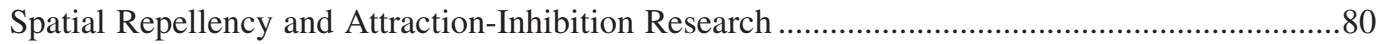

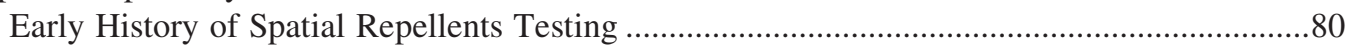

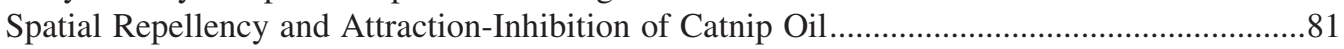

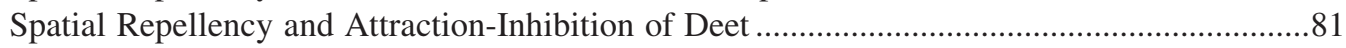

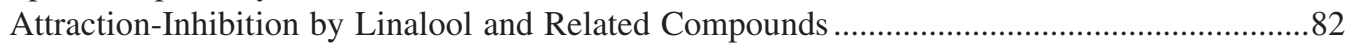

Human-Produced Compounds That Affect Host-Seeking ..................................................... 82

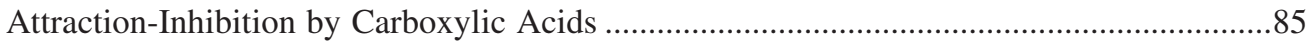

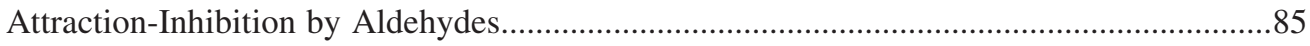

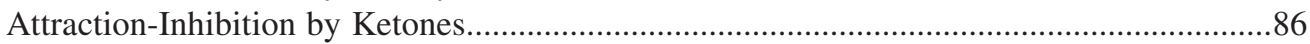

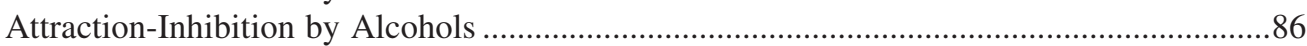

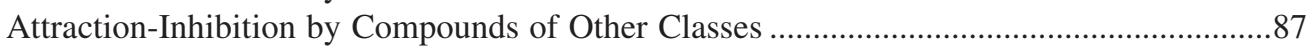

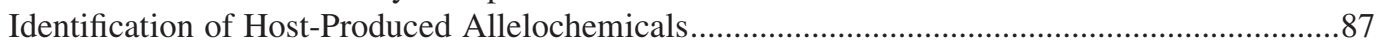

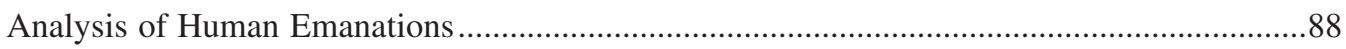

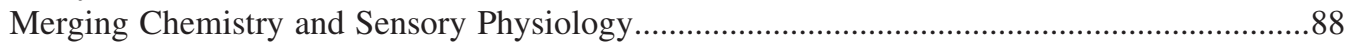

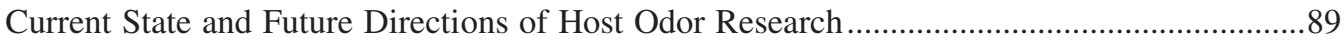

Laboratory Bioassays of Spatial Repellents and Attraction-Inhibitors.......................................89

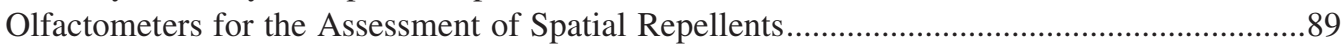

Olfactometers for the Assessment of Attraction-Inhibitors ...................................................... 90

Considerations in the Experimental Design....................................................................90

Correlating Small- and Large-Scale Laboratory Results to Field Experiments ...................91

Field Tests and Use of Spatial Repellents and Attraction-Inhibitors .......................................92

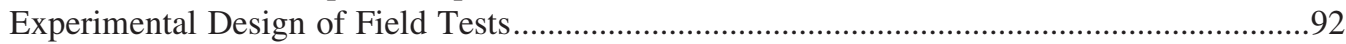

Use of Large-Cage Experiments and Laboratory-Reared Colony Mosquitoes......................92

Experiments with Wild Mosquitoes in the Field ...............................................................92

Use of Stand-Alone Inhibitor-Delivery Technology .............................................................93

Potential Applications of Spatial Repellents and Attraction-Inhibitors.....................................93

Species-Specific or Species-Exclusive Trapping ................................................................. 93 


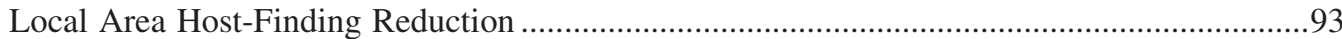

Local Control Using a Push-Pull Strategy with Attractant-Baited Surveillance Traps ............93

Use of Structure-Activity Relationships to Benefit Development of Attraction-Inhibitors ......94

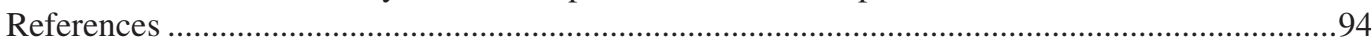

The beginning of knowledge is the discovery of something we do not understand. ${ }^{1}$

\section{Concepts and Terminology Used in This Chapter}

One mechanism by which the action of semiochemicals can be classified is based on the behavioral impact within or external to the species of interest. As such, one can classify a chemical as one of the following ${ }^{2,3}$ :

1. Pheromone, if it results in response between insects of the same species

2. Kairomone, if it results in response in another species that benefits the species receiving the chemical cue

3. Allomone, if it results in response in another species that benefits the species releasing the chemical cue

However, the distinctions can be more specific by classification of chemical cues through the imparted behavioral effect: attractant; repellent; arrestant; locomotory stimulant; feeding, mating, or oviposition stimulant; and feeding, mating, or oviposition deterrent. ${ }^{2,4}$ Karlson and Lüscher first proposed the term "pheromone" to describe chemicals with instraspecific species activity. ${ }^{5,6}$ Chemicals with interspecific species activity are allelochemicals. ${ }^{3}$ Allelochemicals can be separated further into kairomones, of which attractants are a category of, and allomones, which are the primary focus of both this book and chapter, and the class that repellents are a part of. Furthermore, attraction-inhibitors, are classified by us as a category of repellents. Ironically, many of the attraction-inhibitors have been discovered in a search for kairomones used by mosquitoes to locate human hosts. Attraction-inhibitors may not repel by the traditional mechanisms, but they do interfere, or act as an antagonist to the normal attraction response of an insect to attractive odor(s).

The proper name for the behavioral actions that are described in this chapter can be debated extensively and additional discussion of terminology is found in Chapter 2 by White. In this short prequel to the main body of our contribution on human and other compounds that interfere with mosquito host-finding, we put forth our rationale supporting the terms used to describe behaviors reported in this chapter.

\section{Attraction Antagonists and Anti-Attractants}

Attraction antagonist is an appropriate term to describe compounds that interrupt the blood-feeding process in bioassays. The term "antagonism" has been used to describe a phenomenon between two toxicants that is the opposite effect of synergism. ${ }^{7,8}$ Applying this by analogy to attraction, a synergistic response is then a response where the combination of chemicals in a blend produces a level of attraction greater than the sum of attraction response levels to the single substances. Thus, antagonism describes a situation where the attraction to a combination is less than the sum of individual attraction levels. 
Wright et al. ${ }^{9}$ stated that, in principle, these compounds also function as "anti-attractants" in that they disrupt the function of naturally occurring attractants. Wright et al. noted furthermore that repellents and anti-attractants should be considered as separate functional classes of compounds based on their different modes of action.

It is commonly accepted that a volatile chemical attractant is a substance that produces oriented insect movement (positive taxis) or upwind movement (anemotaxis) toward a source by following a concentration gradient of gas-phase molecules distributed in plumes. ${ }^{10}$ Therefore, a broad term is needed to describe compounds that prevent host finding by interference of the positive anemotaxis without too much reliance on characterizing the mechanism of action on the insect. Bearing this mind, compounds that repel using the criteria of Dethier et al. ${ }^{4}$ would be classified as antagonists because the repellent substances prevent host finding by an oriented movement away from the source. However, compounds that cloak or hide the host from mosquitoes that would otherwise be able to locate the host for a blood meal would not fit the strict definition of repellents in the sense of Dethier et al. because the mosquitoes would not necessarily exhibit oriented movement away from the source. ${ }^{4}$

\section{Spatial Repellents and Irritants}

Spatial repellency and irritancy can involve more than simple concealment of host location or attractant odor source. As noted above, a rigorous definition of "repellent" requires movement away from the source. Barton Browne later suggested that "movement away" is not necessarily a suitable criterion, and that "a repellent is almost always assessed in terms of its ability to inhibit the insect's response to chemical attractants..." ${ }^{10}$ This led to the proposal that a repellent is a chemical that, acting in the vapor phase, prevents an insect from reaching a target to which it would otherwise be attracted. However, it should be noted that vapor-phase activity might not be necessary to repel. If contact is made with a surface that contains repellent, then the mosquito chemoreceptors can detect this repellent if it is present at the required threshold concentration to cause repellency. Additionally, it should be apparent that chemical compounds have a vapor phase concentration that is dependent upon their volatilities, and that this concentration falls off as the distance from the source increases. Therefore, the true criterion is linked to the threshold level of chemoreception of (repellent) molecules by the mosquito to elicit the desired behavior (repellency). Obviously, this can occur in space if the mosquito has high sensitivity to the chemical and the chemical has a high vapor phase concentration. Similarly, repellent chemicals that the mosquito is less sensitive to, or that have low vapor phase concentration from low evaporative loss, will result in repellency closer to the surface, or perhaps even by contact.

The use of the word "spatial" to classify repellents was defined by Gouck et al. ${ }^{11}$ as a compound or agent that can produce repellency at a distance. Furthermore, spatial repellents have been described as repellents that inhibit the ability of mosquitoes to locate a target host. ${ }^{12}$ Thus, topical repellents with low vapor pressure, such as $\mathrm{N}, \mathrm{N}$-diethyl-3-methylbenzamide (deet), and highly volatile spatial repellents (attraction-inhibitors) are repellents, even though their modes of action may be radically different.

Another possible source of confusion arises from the term "area repellent." Although spatial repellents should ideally prevent biting in a defined local area, an area repellent does not necessarily require a significant vapor phase spatial repellent effect. An example of this is the use of a repellent that is normally applied topically, such as deet, on a treated net to form a barrier around a perimeter. ${ }^{13}$ For more discussion of area repellents, see Chapter 23 by Strickman.

At times, the term "spatial repellent" is used to describe the action of some pyrethroids. ${ }^{14,15}$ It should be noted that pyrethroids can produce excito-repellency with possible mortality as a result of the exposure. ${ }^{16}$ A pyrethroid with sufficiently high vapor phase concentration, e.g., metofluthrin, ${ }^{15,17}$ can result in a spatial repellent (barrier) effect regardless of knockdown and mortality of insects. In this chapter, the discussion is mostly confined to the natural compounds that impact mosquito behavior by a means of masking attractive odors while minimizing concerns over the mode of action, such as the pyrethroids that exhibit excito-repellency and insecticidal properties. 


\section{Attraction-Inhibitors}

The term "inhibition" has been used to describe a net behavioral effect from a particular mechanism, such as "distension-induced inhibition." 18 Simpson and Wright described the use of low-level continuous emission of a chemical, e.g. Rutgers 612 (2-ethyl-1,3-hexanediol) as a means to "inhibit the normal response" of mosquitoes to an increase in the carbon dioxide gradient. ${ }^{19}$ Although the normal response to carbon dioxide can range from flight activation to oriented positive anemotaxis to the odor source, it is assumed that in this case, the authors expected the normal response to be that of attraction. The term "inhibitor" also denotes a compound that imparts a reduction in trap catches for traps baited with a pheromone. ${ }^{20,21}$ Davis linked a decrease in sensitivity of lactic acid receptor neurons to the inhibition of host-seeking behavior following a blood meal. ${ }^{22}$ If we adopt and apply "inhibitor' in an analogous way to describe these allomones that inhibit the activity of kairomones, these compounds are then inhibitors of attractants (i.e. attraction-inhibitors analogous to pheromone inhibitors described by Roelofs and Comeau, ${ }^{20}$ and Kennedy). ${ }^{22}$ Torr et al. ${ }^{23}$ later expounded on the work of Davis and discussed the manner in which these "attractant-inhibitors" may affect the insects. We have shifted away from calling human-produced masking chemicals "spatial repellents" in recent years and adopted the term "attraction-inhibitors." We believe this term to be a logical choice to describe the observed behavioral effect (inhibition) in bioassays. ${ }^{24,25}$

\section{Spatial Repellency and Attraction-Inhibition Research}

In the mid 1960s, Skinner et al. ${ }^{26}$ collected lipid fractions from human skin exudates and reported that some of these lipid fractions were "repellent" to mosquitoes. They hypothesized that the attraction of mosquitoes to humans was more complex than simply locating a host using kairomones only. It was speculated that the combination of human-produced kairomones and allomones resulted in the overall measured attractiveness of an individual to mosquitoes. ${ }^{26,27}$ Further investigation of the lipid fractions implicated unsaturates as the repellent allomones. ${ }^{28}$ Moreover, measured attraction increased when these lipids were removed from sweat. Skinner et al. ${ }^{29}$ later identified the most repellent of these acids as $\alpha$-linolenic (9,12,15-octadecatrienoic), 2-decenoic, 2-nonenoic, arachidonic (5,8,11,14-octadecatetraenoic), and 10-undecenoic acids. Some saturated fatty acids, e.g., caproic (hexanoic), enanthic (heptanoic), and pelargonic (nonanoic) acids also exhibited high repellency. The carboxylic acids and their effect on host-seeking will be examined more in-depth in Section "Attraction-Inhibition by Carboxylic Acids".

\section{Early History of Spatial Repellents Testing}

The notations of vapor phase, spatial, and area effects from repellents were reported by Christophers in 1945, and this was especially noticed from the action of pyrethrins. ${ }^{30}$ Christophers also noted a distinction between "contact" repellents and "vapour" repellents described by McCulloch and Waterhouse. ${ }^{31}$ A concerted search for "spatial" repellents was undertaken by the USDA in $1948 .{ }^{32}$ Although we will continue to use "spatial" in place of "vapour" repellents, they are both defined by the respective authors as repellents that work "at a distance." "11,31 The USDA effort came about as an offshoot from the established program of topical repellent testing. In their first report of spatial repellents, some of the 110 chemicals tested exhibited repellency, but none were deemed to be outstanding. Results based upon this USDA effort were first described in the literature by Gouck et al. ${ }^{11}$; who reported on the spatial repellency of various esters using time of protection from bites as the means of quantifying the differences in repellency (see Section "Olfactometers for the Assessment of Spatial Repellents" for a description of their bioassay system). Of the esters that were tested, it was reported that the spatial repellency for the mandelates increased as a function of the carbon chain length from $\mathrm{C}_{3}$ to $\mathrm{C}_{8}$, with an 
optimum that occurred at $\mathrm{C}_{5}$. McGovern et al. ${ }^{33}$ used a similar assay system to study other compound classes, and in particular noted that deet was an effective topical repellent, but performed only weakly as a spatial repellent. Maximum spatial repellency occurred in the $\mathrm{C}_{5}$ to $\mathrm{C}_{9}$ range for most of the compound classes tested. Later, other common topical repellents were examined and dimethyl phthalate (DMP) was reported as one of the best spatial repellents against Aedes aegypti ${ }^{34}$; however, Khan and Maibach found deet to be better than DMP using their own biossay methods. ${ }^{35}$ Other noteworthy substances that have been shown to produce spatial repellency of Aedes aegypti include essential oils like citronellal (3,7-dimethyl-6-octen-1-al) and geraniol (E-3,7-dimethyl-2,6-octadien-1-ol), pyrethrums and pyrethroids, and common topical repellents. ${ }^{14}$ Recent efforts to find inhibitory chemicals are directed at natural compounds by examining differences among individual humans of variable attractiveness to biting arthropods.

\section{Spatial Repellency and Attraction-Inhibition of Catnip Oil}

It has been known for some time that volatiles produced from catnip, specifically the isomers of nepetalactone, repel phytophagous insects. ${ }^{36,37}$ Peterson and Coats examined catnip oil and nepetalactone isomers as alternatives to deet for protection from mosquitoes and found these to be more repellent than deet in their bioassay system. ${ }^{38,39}$ Recently, catnip was examined for its ability to inhibit the hostseeking of mosquitoes and was found to be a better attraction-inhibitor than deet, but the less effective repellent of the two based on mean complete protection time (CPT) on a treated cloth affixed to a card above the skin surface. ${ }^{40}$ Further examination of catnip oil and its constituents to deter biting was conducted by Chauhan et al. ${ }^{41}$ The results of their in vivo and in vitro studies were similar in that the biting deterrency of each of the two nepetalactone isomers (Z,E- and E,Z-) and of the racemic mixture were all significant compared to the control, but not different from each other. Tested in vitro, these compounds did not deter biting as well as deet or the repellent, (1S,2S $\left.\mathrm{S}^{\prime}\right)$-2-methylpiperidinyl-3cyclohexene-1-carboxamide (SS220). Further discussion of natural plant and botanical insect repellents are the topics of Chapter 14 by Moore and Hill, and Chapter 15 by Gerberg and Novak, respectively.

\section{Spatial Repellency and Attraction-Inhibition of Deet}

Deet has produced mixed results as a spatial repellent as was mentioned briefly in Section "Early History of Spatial Repellents Testing" and Section "Spatial Repellency and Attraction-Inhibition of Catnip Oil". In some cases, it is weak or less effective than other compounds, ${ }^{11,33,34,40,42}$ and in others it is more effective. ${ }^{14,35,43}$ One possible explanation is that the concentration of deet needs to reach a specific threshold in the vapor phase so that the concentration is sufficiently high enough to affect the mosquito chemosensilla. Otherwise, vapor phase concentrations below this level require landing on a topically treated surface to result in contact with deet at sufficient concentration to act as a biting deterrent and therefore be repellent. Dogan et al. ${ }^{25}$ concluded that deet inhibited the action (attraction) of L-lactic acid, but did not act as a repellent. Dogan and Rossignol noted that just after topical application of deet,$^{24}$ test subjects were still attractive to Aedes aegypti. The results of Bernier et al. ${ }^{40}$ showed that deet inhibits the attraction of mosquitoes, but when compared directly at equivalent dosages, it did not function as an attraction-inhibitor as effectively as catnip oil. It merits mentioning that the individual volunteer whose odors were used in the Bernier et al. study was relatively less attractive to Aedes aegypti than most individuals and this may have produced atypical results. Normally, the mixing of deet into the air stream of a port with human odors does produce a small decrease in the percentage of mosquitoes collected in the olfactometer trap. ${ }^{44}$

Dogan et al. ${ }^{25}$ reported deet to be attractive in the absence of L-lactic acid; this has been reported previously for low doses of deet and Rutgers $612 .{ }^{45} \mathrm{We}$ have also observed this in bioassays with our olfactometer. ${ }^{46}$ In the absence of attractive odors, the clean airstream in our system produces no response (no flight activation nor positive anemotaxis) by the mosquitoes. However, with the release of a 
chemical, upwind anemotaxis and subsequent trapping of a few mosquitoes is observed at times, even when a compound does not attract mosquitoes when tested in competition against a potent attractant (e.g., host odors or chemicals based on host odors). ${ }^{44}$ What appears to be important, at least in the case of deet, is that wind movement contributes significantly to the ability of a compound to repel (or perhaps more appropriately, inhibit host finding) in the vapor phase in both a controlled setting and in the field. $^{43,44,47}$

\section{Attraction-Inhibition by Linalool and Related Compounds}

Alcohols are widely known to repel mosquitoes. For example, citronellol (3,7-dimethyl-6-octen-1-ol), and it's related aldehyde analog, citronellal mentioned in Section "Early History of Spatial Repellents Testing", exhibit spatial repellency of Aedes aegypti in laboratory bioassays. ${ }^{14}$ In fact, essential oils, e.g., citronella Cymbopogon nardus, were the most commonly used repellents prior to the 1940s. ${ }^{37}$ Interestingly, citronella oil contains primarily geraniol; however, citronellol and citronellal were reported as the active ingredients leading to repellency. ${ }^{48,49}$ Linalool (3,7-dimethyl-1,6-octadien-3-ol) is a waterinsoluble alcohol that is a colorless liquid and is used commonly by the perfume and cosmetics industry because of its appealing flowery odor. It can be found naturally in such sources as apricots, carrots, lavender, cardamom and marjoram. Human inhalation of this compound is known to produce sedation, and it has been shown to suppress the voltage-gated currents in newt olfactory receptor cells. ${ }^{50}$ Birkett et al. ${ }^{51}$ reported that linalool produced significant electroantennogram (EAG) responses in four species of biting flies, and reduced the upwind (positive) anemotaxis in laboratory wind tunnel studies.

Linalool has two optically active isomers; researchers have found the $(\mathrm{S})-(+)$-enantiomer to be the better attraction-inhibitor. ${ }^{52}$ Using a dual-port triple-cage olfactometer, ${ }^{46}$ Kline et al. examined the impact of linalool, dehydrolinalool (3,7-dimethyl-6-octen-1-yl-3-ol), and deet on the host-seeking ability of laboratory-reared Aedes aegypti. ${ }^{53}$ Compared to dehydrolinalool and deet in competitive bioassays, linalool was the most potent inhibitor (competitive bioassays are defined in Section "Considerations in the Experimental Design"). An important finding of this work was that the release of linalool resulted in two observable effects on mosquito behavior. The first effect was that fewer mosquitoes in the cage were activated to flight from concomitant release of attractant plus linalool in the airstreams of separate ports of the dual-port olfactometer. This indicated that vapor phase linalool acted as an attraction-inhibitor by preventing some of the mosquitoes from detecting the normally attractive odors. The second observable effect was that of the mosquitoes that were activated to flight, fewer than normal numbers of these were able to locate the odor source. This indicated that even though some mosquitoes could detect the presence of attractive odors, they were not as capable of orienting towards and, thus, locating the odor source.

\section{Human-Produced Compounds That Affect Host-Seeking}

The skin surface of humans differs greatly from that of other animals. Except for a few specific localized areas, human skin normally ranges from $\mathrm{pH} 4.2-6.0$ due to the abundance of fatty acids that are present. ${ }^{54,55}$ In addition to carboxylic acids, skin also has high levels of triglycerides and squalene; however, it is the acids that contribute largely to the types of microbes that can exist on skin. ${ }^{56,57}$ Humans are the only animal to exhibit acne vulgaris, and within the comedo of acne, there are high levels of fatty acids. ${ }^{58}$ The distribution of saturated fatty acid molecular sizes are clustered in the $\mathrm{C}_{12}-\mathrm{C}_{20}$ and $\mathrm{C}_{21}-\mathrm{C}_{30}$ ranges, of which $\mathrm{C}_{16}$ and $\mathrm{C}_{18}$ in the former and $\mathrm{C}_{24}$ in the latter are present in the highest relative abundance. ${ }^{59}$ The most abundant unsaturated fatty acids are palmitoleic (9-hexadecenoic), oleic (9-octadecenoic) and linoleic (9,12-octadecadienoic) acids.

While some studies have focused on endogenous lipid production, others have focused more on the end products, or volatiles that are released by metabolic activity via respiration through the skin, or from degradation of skin surface compounds by microbial action. Sastry et al. ${ }^{60}$ assembled a comprehensive treatise of human-produced compounds, covering how these compounds can be used in the diagnosis of 
diseases and in the interpretation of human metabolism. In their review of the subject, they highlighted studies that identified chemically underivatized compounds, such as that of Ellin et al. who reported the identification of over 130 compounds in a study of total human body emanations. ${ }^{61}$ Among the high levels of acids, there were also significant volatile constituents identified that consisted of alcohols, ketones, aldehydes and other chemical compound classes. For example, acetone and isoprene (2-methyl1,3-butadiene) were two of the most abundant components, emitted at rates of $240-470$ and $251-425 \mu \mathrm{g} / \mathrm{h}$, respectively, for the three subjects that were examined by Ellin et al. ${ }^{61}$ In a later study, Naitoh et al. determined the release rate of acetone from human skin and reported a range as $80-800 \mathrm{pg} / \mathrm{cm}^{2} \mathrm{~min} .{ }^{62} \mathrm{In}$ our own studies, we knew of one individual (volunteer A in Table 4.1) who consumed alcohol regularly. This subject was consistently the most attractive to Aedes aegypti of the six subjects who participated in this study. Of the most volatile emanations quantified, the most attractive individual (A) produced the highest level of acetone, ethanol, and methanol. Shirai et al. ${ }^{63}$ reported that landings of the Asian tiger mosquito, Aedes albopictus increased after consumption of a beverage containing ethanol. They measured both skin temperature and the ethanol in the perspiration of human subjects, but they did not find a relationship between either of these two variables and the landing rates.

Similar to Sastry et al. ${ }^{60}$ we also prefer the analysis of volatiles without chemical derivatization for the identification of human skin (and other host) emanations that may affect mosquito host-seeking. ${ }^{64}$ Mosquitoes detect volatile host-finding cues in the gas phase, so we believe that minimization of complexity in the sampling process will tend to cause the least change or bias toward the compound classes and proportions of each chemical detected. The relative abundances of many of the volatile compounds have a significant impact on the overall attraction process. Additionally, it is important to avoid comparing too closely human and mosquito olfaction. The odor of human perspiration that we smell is due inpart to saturated and unsaturated $\mathrm{C}_{6}-\mathrm{C}_{11}$ acids and one of the most abundant odiferous compounds is (E)-3-methyl-2-hexenoic acid. ${ }^{60,65,66}$ The sensitivity of humans to the odor of these compounds does not necessarily imply that these same compounds have a role in mosquito host finding.

\section{TABLE 4.1}

Comparison of Volatile Compounds Emanated from Six Different Humans

\begin{tabular}{|c|c|c|c|c|c|c|}
\hline \multirow[b]{2}{*}{$\begin{array}{l}\text { Compound } \\
\text { (Class) }\end{array}$} & \multicolumn{6}{|c|}{ Human Subject } \\
\hline & $\mathbf{A}$ & B & $\mathbf{C}$ & D & $\mathbf{E}$ & $\mathbf{F}$ \\
\hline \multicolumn{7}{|l|}{ (Aldehydes) } \\
\hline Acetaldehyde & 160 & 83 & 74 & 52 & 190 & 172 \\
\hline $\begin{array}{l}\text { 2-Methyl-2- } \\
\text { propenal }\end{array}$ & 2.2 & 1.4 & 6.5 & 1.5 & 8.3 & 7.8 \\
\hline 2-Methylbutanal & 2.5 & 1.3 & 0.92 & 0.87 & 4.6 & 4.7 \\
\hline $\begin{array}{l}\text { Hexanal } \\
\text { (Ketones) }\end{array}$ & 5.4 & 6.2 & 8.1 & 6.4 & 29 & 38 \\
\hline Acetone & 900 & 50 & 24 & 45 & 168 & 200 \\
\hline 2-Butanone & 1.3 & 0.30 & 0.39 & 0.33 & 1.0 & 0.82 \\
\hline $\begin{array}{l}\text { 2,3-Butanedione } \\
\text { (Alcohols) }\end{array}$ & 2.2 & 1.4 & 6.5 & 1.5 & 8.3 & 7.8 \\
\hline Methanol & 638 & 6.9 & 4.1 & 8.1 & 13 & 13 \\
\hline $\begin{array}{l}\text { Ethanol } \\
\text { (Sulfides) }\end{array}$ & 638 & 219 & 4.1 & 117 & 18 & 45 \\
\hline Carbon disulfide & 0.38 & 0.12 & 0.13 & 0.33 & 1.7 & 0.55 \\
\hline
\end{tabular}

The headspace of forearm emanations was collected in a Tedlar bag and analyses conducted by microscale purge and trap GC/MS. Values are in parts per billion by volume (ppbv).

Source: From M. M. Booth, Unpublished results, 1997. With permission. 
Bernier et al. ${ }^{67}$ used gas chromatography/mass spectrometry (GC/MS) of compounds adsorbed and then thermally desorbed from glass beads to identify 277 compounds present on the skin of humans. They used columns with different stationary phase polarities to perform the chemical separation of samples collected from four subjects (males ranging from 26 to 61 years in age). The composition of emanations was qualitatively similar for all subjects, but quantitative differences were readily observed. This study provided the groundwork to explore chemical differences between individuals who represented the extremes of low and high attractiveness to biting mosquitoes. The same study also examined day-to-day chemical changes correlated to changes in laboratory measured mosquito attraction for a single individual. ${ }^{68}$ In the comparison of two different subjects, the individual who was more attractive to Aedes aegypti had, on average, higher levels of lactic acid, butanone, 2-pentanone, 3-pentanone, and 6-methyl-5-hepten-2-one. The less attractive host had a higher level of methylpentanol, 1,3-butanediamine, capric acid (decanoic acid), lauric acid (dodecanoic acid), heptanal, and pelargonaldehyde (nonanal). From studies of a single individual, nonanal, 6-methyl-5-hepten-2-one, and benzaldehyde were less abundant in the emanations on the day that the residuum was more attractive to mosquitoes. Those individuals who were less attractive to Aedes aegypti tended to have the highest concentrations of aldehydes, particularly nonanal, on their skin. ${ }^{68,69}$ Thus, aldehydes appear to have an important role in the balance of attraction and inhibition.

Human fingerprint residues have been examined to identify gender-specific and age differences in the lipids. ${ }^{70}$ Hexadecenoic, palmitic (hexadecanoic), and octadecenoic acids were among the most abundant acids observed, in agreement with Ansari et al. ${ }^{59}$ Although these three acids occur at higher relative abundances in males compared to females, the differences were not statistically significant. Curran et al. ${ }^{71,72}$ examined male and female odors over time and after exercise. They described a classification of detected compounds based upon the origin of the odors. "Primary odors" were comprised of emanations that were present regardless of sampling date or time. Compounds that originated from dietary or environmental factors were considered secondary odors. Tertiary odors were those attributable to exogenous factors that resulted in adherence of a chemical to the outer layer of the skin. Using this terminology, the base attraction of mosquitoes to human hosts would be associated with the primary odor components, with some differences possibly found in the secondary odors and less likely in the tertiary odors. Finally, before focusing on the specific compound classes in human emanations, it is interesting to note the similarities of constituents for skin compounds compared to those found in the oral cavity, urine and alveolar breath.

Oral odors are comprised primarily of sulfides, ethanol, diacetyl (2,3-butanedione), acetone, acetaldehyde, and methyl mercaptan (methanethiol). ${ }^{60}$ Acetaldehyde and other aldehydes are also detectable in blood and breath. ${ }^{73,74}$ Many of the short-chain ketones, acids, and hydroxy acids, such as L-lactic acid, are also present in human urine. Breath has been reported to contain hundreds of detectable compounds, ${ }^{75,76}$ and many of these constituents overlap with those present in blood, ${ }^{60,77}$ urine, ${ }^{60}$ and on the skin. ${ }^{67,72}$ It is fairly obvious that exhaled breath contains large quantities of carbon dioxide and this is one of the most universally known behavioral activators and trap attractants for mosquitoes. ${ }^{78-82}$ However, breath also contains compounds that inhibit the host-seeking response, as was shown for Anopheles gambiae. ${ }^{83}$ Therefore, in addition to known Aedes aegypti attractants (e.g., acetone, dimethyl disulfide (DMDS), and 2-pentanone) in human breath, there are also attraction-inhibitors, e.g., nonanal. ${ }^{75,76}$ From attraction studies, it was evident that certain combinations of chemicals and classes of chemicals when combined with L-lactic acid resulted in blends with much lower than expected attraction of mosquitoes in laboratory bioassays. ${ }^{64,84,85}$ For example, in Bernier et al ${ }^{84}$ some branched ketones and aldehydes that were combined with L-lactic acid resulted in attraction responses that were less than that of L-lactic acid alone (26\% in this study). Some of these specific compounds and functional groups are discussed in greater detail in the next few subsections. While generalizations can be made about specific compounds and their ability to attract and inhibit, it is crucial to keep in mind that the reported behavioral effect is heavily dose-dependent. Specifically, some compounds that attract at low vapor-phase concentrations may inhibit, arrest, or repel insects at higher concentrations [viz. the response of deet described in Section "Spatial Repellency and Attraction-Inhibition of Deet"]. 


\section{Attraction-Inhibition by Carboxylic Acids}

Saturated and unsaturated fatty acids are abundant in skin emanations. Other substituted acids such as L-lactic acid are also present at relatively high levels, and dicarboxylic acids can be detected as some of the constituents deposited on handled glass beads. ${ }^{67} \mathrm{~L}$-lactic acid is a hydroxy acid that is expected to be present at substantial levels because it is formed in the body from metabolism of proteins and carbohydrates under anaerobic conditions. Ellin et al. also detected another important metabolic product, pyruvic acid, which is an oxo acid that plays a vital role in human metabolism under aerobic conditions. ${ }^{61}$

The initial discovery that fatty acids resulted in "repellency" (inhibition of host-seeking in bioassays) was reported by Skinner et al. as noted in Section "Spatial Repellency and AttractionInhibition Research" ${ }^{26}$ Examination of the volatile acids used in blends developed to attract Aedes aegypti led to discoveries about the compounds that inhibit host-seeking, specifically that addition of some saturated acids to blends decreased the attraction. Bosch et al. used a Y-tube olfactometer to demonstrate that combinations of L-lactic acid and either butanoic $\left(\mathrm{C}_{4}\right)$ or any of the $\mathrm{C}_{9}-\mathrm{C}_{12}$ acids resulted in a composition that did not produce a significant increase in the attraction of female Aedes aegypti compared to the attraction to L-lactic acid alone. ${ }^{86}$ For binary blends of L-lactic acid and either propanoic $\left(\mathrm{C}_{3}\right)$ or pentanoic $\left(\mathrm{C}_{5}\right)$ acids, they observed that addition of either undecanoic $\left(\mathrm{C}_{11}\right)$ or myristic (tetradecanoic) $\left(\mathrm{C}_{14}\right)$ acids to this blend resulted in a significant decrease in attraction. Smallegange et al. reported that a blend of 12 carboxylic acids was repellent against Anopheles gambiae when tested alone or with L-lactic acid. ${ }^{87}$

Constantini et al. reported that the electrophysiologically active acids that produce the odor in human perspiration, such as Z- and E-3-methyl-2-hexenoic acid, and 7-octenoic acid, repelled or masked the presence of attractants, and that these may be involved in the avoidance of nonpreferred individuals for blood meals. ${ }^{88}$ These findings and those of Bosch et al. ${ }^{86}$ provide compelling support to the view that as the concentration of constituents in the human odor profile is perturbed greatly, it can result in hostavoidance behavior by mosquitoes.

Reifenrath indicated that acids in the $\mathrm{C}_{6}$ to $\mathrm{C}_{8}$ range coupled with $\mathrm{C}_{8}-\mathrm{C}_{12}$ acids were repellent to arthropods, and that binary combinations of octanoic $\left(\mathrm{C}_{8}\right)$ and nonanoic $\left(\mathrm{C}_{9}\right)$ acids, or the tertiary combination of $\mathrm{C}_{8}-\mathrm{C}_{10}$ acids effectively prevented host location. ${ }^{89}$ Reifenrath examined repellency of Aedes aegypti by treating gauze or polyester film with each acid applied at $0.3 \mathrm{mg} / \mathrm{cm}^{2}$. These experiments indicated that 2-pentenoic, 2-octenoic, 3-methyl-2-octenoic, nonanoic, decanoic, and undecanoic acids were the most effective. Topical tests on human skin showed that the most repellent compounds were 4-methyloctanoic, 3-methyl-2-octenoic and nonanoic acids, implicating the most repellent compounds as those that contain 9 carbons and to some extent 8 and 10 carbons [viz. nonanal discussed throughout this chapter, but also the $\mathrm{C}_{8}$ and $\mathrm{C}_{10}$ carbon compounds such as linalool, citronellol, citronellal, dehydrolinalool in Section "Spatial Repellency and AttractionInhibition of Deet" and Section "Attraction-Inhibition by Linalool and Related Compounds", geraniol in Section "Early History of Spatial Repellents Testing", and Z-4-decenal and octanal in Section "Attraction-Inhibition by Aldehydes"].

\section{Attraction-Inhibition by Aldehydes}

Aldehydes have received attention recently because they have been identified as the repellent compounds in the emanations of the crested auklet (Aethia cristatella).$^{90-93}$ Three of the four reported repellents are aldehydes, hexanal, octanal, and Z-4-decenal, and one is an acid, hexanoic acid. Additional discussion of these compounds and chemical defenses of birds and other vertebrates is found in Chapter 3 by Weldon and Carroll. Although nonanal was not identified in emanations of the crested auklet, it has been reported as a major constituent of emanations from the whiskered auklet (Aethia pygmaea). ${ }^{91}$ Nonanal appears to be detected not only by mosquitoes, but other blood-feeding arthropods as well. Steullett and Guerin demonstrated that numerous aldehydes, including hexanal, heptanal, nonanal, benzaldehyde, and methyl-substituted benzaldehydes stimulated tarsal chemoreceptors of the tick Amblyomma variegatum, 
another arthropod that relies at least in part on chemical cues for host location. ${ }^{94}$ Guerenstein and Guerin identified nonanal as the compound that elicited an electrophysiological response from a receptor on the basiconic sensillum of triatomine bugs (Triatoma infestans) ${ }^{95}$ In that study, nonanal was also identified chemically by GC/MS in the extracts of sheep wool and chicken feathers. The unsaturated and diunsaturated aldehydes tested in their study did not produce an electrophysiological response, nor did other $\mathrm{C}_{9}$ compounds, including nonanoic acid, 2-nonanone, and nonanol. Heptanal and octanal also produced linear responses in the sensillum cells, but other saturated aldehydes $\left(\mathrm{C}_{6}, \mathrm{C}_{10}-\mathrm{C}_{12}\right)$ did not. Interestingly, researchers have previously observed a linear correlation of attraction and repulsion to the concentration of aliphatic aldehydes in blowflies. ${ }^{37,96}$

Aldehydes are commonly reported in residue from human skin; these are predominantly in the $\mathrm{C}_{6}-\mathrm{C}_{10}$ range. ${ }^{72}$ Haze et al. documented that the concentration of 2-nonenal, an unsaturated analog of nonanal, is related to the age of an individual with higher levels observed in males over 40-year-old and that all subjects produced detectable quantities of $\mathrm{C}_{6}-\mathrm{C}_{10}$ saturated aldehydes in this study. ${ }^{97}$ In contrast, Curran et al. was able to detect 2-nonenal in females and in individuals less than 25-year-old. ${ }^{71,72}$ Curran et al. reported that the $\mathrm{C}_{8}-\mathrm{C}_{10}$ aldehydes were detectable in $88 \%$ of their subjects, ${ }^{71}$ and Zhang et al. also reported these $\mathrm{C}_{8}-\mathrm{C}_{10}$ aliphatic aldehydes. ${ }^{98} \mathrm{~A}$ better understanding about the role of $\mathrm{C}_{8}-\mathrm{C}_{10}$ aldehydes in the mosquito host-finding process may benefit from experiments comparing the relative attractiveness of subjects who have high or low concentrations of these compounds on their skin.

Bernier et al. used microscale purge and trap GC/MS to identify aldehydes from butanal to undecanal, with nonanal as the most abundant in this series. ${ }^{64}$ The cryo-focused GC/MS analysis of glass beads allowed the detection of propanal $\left(\mathrm{C}_{3}\right)$ to nonanal $\left(\mathrm{C}_{9}\right)$, including branched and unsaturated analogs of these compounds. The more volatile aldehydes are partly responsible for off odors in spoiled meat, ${ }^{99}$ while the less volatile, such as octanal, nonanal, and benzaldehyde have a more pleasant floral aroma. Endogenous aldehydes that are oxidized from their respective acids are hexanal from linoleic and arachidonic acids; heptanal from palmitoleic acid; and nonanal from oleic acid. ${ }^{74,100}$ As noted earlier in this chapter, these acids are the some of the most abundant in human emanations. ${ }^{59,67,70}$ By analogy, this may partly explain the abundance of these specific aldehydes in human emanations. ${ }^{64}$

\section{Attraction-Inhibition by Ketones}

Acetone is the most abundant ketone in human odors (see Table 4.1) ${ }^{61,62}$ One mechanism for endogenous production of this compound is from fat metabolism. ${ }^{62}$ In addition to acetone, numerous 2- and 3-substituted ketones, as well as cyclohexanone, have been reported in human odors. ${ }^{61}$ Unsaturated ketones have also been found in the residue of more than $50 \%$ of human subjects. ${ }^{72}$ Birkett et al. ${ }^{51}$ reported that when the unsaturated branched ketone, 6-methyl-5-hepten-2-one, was applied to cattle, it reduced the attraction to biting flies.

Saturated ketones, particularly in the $\mathrm{C}_{7}-\mathrm{C}_{12}$ range have been found to inhibit mosquitoes. ${ }^{101}$ The combination of L-lactic acid with either acetone or butanone, the smallest and most volatile of the saturated ketones, produced synergistic attractant blends for Aedes aegypti. ${ }^{101,102}$ However, as larger saturated ketones within the series, like pentanone $\left(\mathrm{C}_{5}\right)$ and hexanone $\left(\mathrm{C}_{6}\right)$, are blended with L-lactic acid, the attraction drops from synergistic to additive, and then results in inhibition of attraction for blends with heptanone $\left(\mathrm{C}_{7}\right)$ through dodecanone $\left(\mathrm{C}_{12}\right)$. When chain lengths exceed $\mathrm{C}_{12}$ in the ketones $\left(\mathrm{C}_{10}\right.$ in acids and aldehydes) it is expected that the volatility decreases below a threshold level such that the vapor phase concentration is so low that the impact on host-seeking disappears. This effect was also evident when researchers examined the repellency of alcohols larger than decanol. ${ }^{37}$

\section{Attraction-Inhibition by Alcohols}

Bernier et al. ${ }^{67}$ identified unsaturated and saturated alcohols from butanol to heptadecanol were in human skin. Ellin et al. also observed a number of these alcohols and ethylene glycol. ${ }^{61}$ Glycerol also was 
reported in both studies; it is a major breakdown product of bacterial action on triglycerides. ${ }^{56}$ Phenol was produced by all human subjects in the study of Curran et al. ${ }^{72}$ In addition to amides like deet, aliphatic alcohols have been popular historically as insect repellents, e.g., the series of decanol $\left(\mathrm{C}_{10}\right)$ through tetradecanol $\left(\mathrm{C}_{14}\right),{ }^{103}$ and Rutgers 612. ${ }^{104,105}$ Dogan and Rossignol examined various fragrances and compositions that contained alcohols such as geraniol and dimethyl cyclormol (hexahydrodimethyl methanoinden-5-ol) and found these to either inhibit or repel mosquitoes in a modified FeinsodSpielman olfactometer. ${ }^{24}$

In contrast to the well known attractant 1 -octen-3-ol, ${ }^{106,107}$ several related, more volatile unsaturated alcohols, including linalool will inhibit attraction by Aedes aegypti in laboratory bioassays. ${ }^{53,108}$ Yet, other unsaturated alcohols, such as geraniol, ${ }^{24}$ or diols that are similar in structure, such as 7-octen-1,2diol, have little or no effect on the host-seeking of Aedes aegypti. ${ }^{108}$ The examination of compounds from cattle to identify compounds that affect host location by five species of biting flies revealed that 1-octen3-ol and 3-octanol were attractants in wind tunnel studies. In contrast, these compounds reduced the number of biting flies on cattle in the field. ${ }^{51}$ This may be a case where the normal host odor profile is perturbed so greatly by the added volatiles that host avoidance by the insects is the net result.

\section{Attraction-Inhibition by Compounds of Other Classes}

Researchers have documented ammonia and a series of amines from methylamine to butylamine in human emanations. ${ }^{61,109}$ Ammonia is formed through amino acid catabolism, and along with urea and uric acid are the three main nitrogen-containing compounds excreted by animals. ${ }^{110}$ Ammonia has been demonstrated to attract Aedes aegypti and Anopheles gambiae at low concentrations, ${ }^{111,112}$ and to deter feeding at higher doses. ${ }^{87,113}$ In addition to these alkaline substances, Bernier et al. also reported a substantial number of hydrocarbons and heterocyclic compounds present in human emanations. ${ }^{67}$ Some of these are currently being tested in our laboratory to determine if they play a role in the host-seeking behavior of mosquitoes. Bernier et al. identified some sulfides and some 1-chloroalkanes in human skin emanations. ${ }^{67}$ Sulfides and chlorides have not been observed to inhibit the host-seeking of Aedes aegypti $^{101}$; however, larger sulfides, chlorides and other alkyl halides have not yet been tested as attraction-inhibitors.

If we attempt to make a general statement regarding compounds capable of attraction-inhibition, then we could base this upon the presence of oxygen in the molecule, as Bunker and Hirshfelder noted for "good" repellents in $1925 .{ }^{114}$ Roadhouse later noted that many effective repellents contain nitrogen. ${ }^{115}$ However, this should be kept in perspective because many compounds contain oxygen, nitrogen, or both and do not show effective repellency or inhibition of mosquito host-seeking. ${ }^{115,116}$

\section{Identification of Host-Produced Allelochemicals}

Numerous techniques exist to sample, collect, concentrate, chemically separate, and identify compounds in host emanations. There are benefits and drawbacks to each choice. One needs to consider all of these factors carefully when selecting the approaches to solve a complex problem, such as the identification of chemicals that affect mosquito host-seeking behavior. It is important to realize that a single method in any of these processes is likely to prove inadequate for the resolution of a complex situation involving potentially numerous compounds that can span a wide range of differing compound polarities and volatilities. For example, multiple preconcentration techniques may be needed to provide complementary information, and multiple chromatography columns with stationary phases of different polarities may need to be used to resolve all of the compounds. ${ }^{64,67}$ By combining information from different types of analyses, the total chemical profile will be more complete. Some of the more recent techniques applied to the analysis of human emanations have either involved solvent extraction, 
deposition onto glass beads, or the use of solid phase microextraction (SPME) fibers as noted in Section "Analysis of Human Emanations".

\section{Analysis of Human Emanations}

The analytical method of choice for almost all comprehensive chemical analyses of volatile human body emanations has involved chromatographic separation followed by mass spectrometric detection, e.g., GC/MS, whether the emphasis is on skin emanations, breath, urine, blood, oral cavity, or the total composite of emanations from an entire person. ${ }^{60,61,64,67,68,70-72,75,76,98,109,117,118}$ Mass spectrometry allows for the identification of compounds based on the fragmentation pattern of compounds. These patterns consist of differing intensities of ions (technically, as a ratio of mass to charge, $\mathrm{m} / \mathrm{z}$ ) that result from bombardment of sample molecules by electrons. There are various types of mass analyzers for mass spectrometers, but the most common for these studies are either magnetic/electric sector or quadrupole instruments because they provide mass spectra that is most similar, and therefore the most easily matched, to mass spectra in existing computerized mass spectral libraries.

In many of these analyses, hundreds of compounds are present. Therefore, separation must be effected prior to mass spectral analysis. This is accomplished by column chromatography. Over the last few decades, the columns employed for this purpose have improved greatly. They are more stable due to better phase bonding, allow greater sample capacity, and are capable of better resolution. Despite all of these improvements, exposure to air and/or extreme hot or cold temperatures still easily degrade the GC column stationary phase. In general, the more polar that the column phase is, the more constrained that it will be with respect to temperature limits than a column that has a relatively nonpolar stationary phase.

Soxhlet extraction, commonly used for fat and oil extraction, followed by GC/MS was used to concentrate and identify volatiles from foot stockings. ${ }^{119}$ Bernier et al. used glass beads to collect emanations for subsequent thermal desorption into a GC injection port. ${ }^{64,67,68}$ In doing so, the problems from the high water content of perspiration was avoided. This remedy is significant because loading water onto gas chromatography columns is detrimental to the stationary phase. Asano et al. used glass beads followed by solvent extraction of compounds from the beads to study fingerprint residues. ${ }^{70}$ Headspace GC/MS was used to analyze age-specific male individual odor differences, ${ }^{97}$ and SPME has been used to collect and concentrate skin volatiles for subsequent identification and quantitation by GC/ MS. ${ }^{71,72,98,118}$ In the work of Curran, ${ }^{72}$ supercritical fluid extraction (SFE) was used as a pretreatment to reduce or eliminate some of the background compounds in the gauze, which was necessary for quantitation of human emanations because a number of human emanations also are measurable in the background contaminants from the gauze. This innovative pretreatment reduced exogenous compounds and allowed them to achieve accurate quantitative results.

\section{Merging Chemistry and Sensory Physiology}

One of the earliest reports of detection of electrical impulses along the nerves was that of Adrian, who in 1930 recorded the discharge of the caudal nerve in the caterpillar. ${ }^{120}$ Electrophysiological studies of these impulses based upon selection of innervated nerve has contributed significantly toward an understanding of which compounds and which sensory organs may factor into the process of host attraction or other behavioral responses. Electroantennograms provide an ideal screening tool for compounds that insects detect, although it does not reveal whether this detection may lead to attraction, avoidance, repellency, or other behaviors. Single-cell recording can determine precisely which receptor organ a compound stimulates. In the early days of these techniques, Roelofs used GC to separate compounds and coupled the resulting sample stream with EAG to identify pheromones and compounds that are synergists and inhibitors for pheromones. ${ }^{20,121,122}$ 
Combination of these techniques with gas chromatographic separation is a powerful approach to analyze complex samples for the compound (peaks) that produce bioactivity. By either routing the sample via column splitting to both instruments (GC-EAD and GC/MS), or simply injecting the same sample on separate instruments with the GCs configured similarly, it is possible to identify and thus focus on a smaller set of compounds that are bioactive in a sample that may contain hundreds of compounds. Recent applications of this technique can be found in the report of Cork et al. ${ }^{123}$ and related studies involving mosquitoes, such as Anopheles gambiae. ${ }^{117,124-126}$ Working with Anopheles gambiae antennae, Cork and Park examined extracted human skin compounds and identified the most abundant acids as acetic, heptanoic, and hexadecanoic acids, whereas the EAG responses were greatest for formic, pentanoic, butanoic, propanoic, acetic, and hexanoic acids, all of which were more intense than the response to the 1-octen-3-ol standard. ${ }^{117}$ Constantini et al. ${ }^{88}$ examined EAG responses of common human-produced odiferous compounds in sweat and evaluated their impact on host-seeking using a wind tunnel for bioassay as reported in Section "Attraction-Inhibition by Carboxylic Acids". Other successful recent electrophysiological studies with additional arthropods have been reported for tsetse flies, ${ }^{106,127}$ ticks, ${ }^{94}$ and the New World screwworm. ${ }^{128}$

\section{Current State and Future Directions of Host Odor Research}

Section "Attraction-Inhibition by Carboxylic Acids" described a recent example of the application of allomonal odors in which Reifenrath added carboxylic acids to host emanations to make the normally attractive host appear to have a different chemical profile. ${ }^{89}$ The result was that the host was much less attractive to biting insects. At present, host-odor research continues with increased emphasis on understanding how kairomones and allomones function together to mediate the overall behaviors in the host-seeking process of arthropods. Some of the studies involve human hosts for anthrophophilic species that transmit malaria, such as Anopheles gambiae and Anopheles albimanus, or for those that transmit dengue and yellow fever, such as Aedes aegypti. Other studies center on birds, the preferred hosts of ornithophilic species such as Culex tarsalis, Culex pipiens quinquefasciatus and Culex nigripaplus, which are vectors of West Nile Virus (WNV) in North America. Studies involving animals as sources of chemicals that may attract arthropods, repel them, or inhibit the attractive emanations of a host is the subject of Chapter 3 by Weldon and Carroll.

\section{Laboratory Bioassays of Spatial Repellents and Attraction-Inhibitors}

The information derived from a particular study depends heavily upon the bioassay because the construction design of the device and the procedure used determine the behaviors that are assessed. The subject of this section is the common laboratory bioassay devices that have been used to produce many of the results described in this chapter. Additional coverage of olfactometer design and usage can be found in Chapter 9, written by Butler.

\section{Olfactometers for the Assessment of Spatial Repellents}

One can trace the design of dual-port olfactometers back to the 1930s. ${ }^{129-131}$ Early USDA spatial repellency studies employed a similar style single-cage olfactometer modified to hold mesh netting in the trap ports. ${ }^{132,133}$ Researchers conducted tests by passing air over a human arm and through a trap into the cage where 100 mosquitoes were located. The mesh cotton netting within the traps was either treated or untreated (as the control) with candidate spatial repellents. The test period was $5 \mathrm{~min}$ and netting was tested every other day until two successive trials resulted in $>10 \%$ of the test mosquitoes trapped in the 
port with human odors. Thus, effectiveness of compounds was evaluated based on days of duration of repellency.

Skinner and colleagues also used a dual-port olfactometer, operated in noncompetitive and competitive modes (see Section "Considerations in the Experimental Design" for a description of these modes) to compare two treatments consisting of human lipid fractions. ${ }^{26-29}$ Researchers also quantified the repellency by the location of mosquitoes in the test and control ports after allowing the insects to fly upwind and select a port. In the noncompetitive mode, they compared the ratio of mosquitoes captured in the control port to the number in the sample port and the greater the ratio, the higher "repellency" according to this index. Because this experiment did not allow contact between mosquito and attractant, we believe that operation of the olfactometer in this way measured the attraction-inhibition of specific compounds. Dogan and Rossignol modified a Feinsod-Spielman olfactometer by constructing an additional chamber to allow measurement of "repellent" response based on insects moving away from the treatment. ${ }^{24}$ Recently, Grieco et al. ${ }^{134}$ designed a modular bioassay device which can be assembled to provide a system to screen contact irritancy of candidate chemicals, and reconfigured in a manner to allow assessment of spatial repellency. The movement of chemical inside each of these olfactometers is accomplished by convection and diffusion, without supplementation of a stream of air.

\section{Olfactometers for the Assessment of Attraction-Inhibitors}

Barrows first used the Y-tube olfactometer in studies of flies. ${ }^{135}$ Geier et al. and Bosch et al. have used recent models to test mosquito responses. ${ }^{86,136}$ The triple-cage dual port olfactometer constructed by Posey et al. $^{46}$ and used in our laboratory is based on older designs described in Section "Olfactometers for the Assessment of Spatial Repellents". ${ }^{132,133}$ Because all of these olfactometer designs employ two ports, they can be used to measure attraction response to either a single treatment versus a control, or to two individual treatments in competition. Reifenrath used a Feinsod-Spielman olfactometer to measure the repellent effect imparted by carboxylic acids on human odors. ${ }^{89}$ The design of this olfactometer allowed odors to pass through a linear arrangement (similar to Grieco et al. ${ }^{134}$ ) of chambers by (in this case) a fan that drew the odors upward into the top chamber. Prior to conducting a test with human odors, mosquitoes were released in the top chamber, and allowed to distribute between the two chambers. After human odors were introduced through the bottom of the olfactometer, the mosquitoes that flew from the upper chamber down to the lower chamber were counted as responding to an attractive stimulus. Those remaining in the upper chamber were considered "repelled." Again, this may not be truly indicative of repellency-it can be reasonably argued that mosquitoes that remain in the top part could be inhibited from detection of potentially attractive odors, or simply nonresponding. Provided that a standard is assessed with this design, then a reduction in attraction can be attributed to either the effect of a spatial repellent or attraction-inhibitor.

As noted above, the standard design of the Y-tube, or dual-port olfactometer (without modification inside the traps) is perhaps not the best bioassay system to measure spatial repellency because one cannot discern whether mosquitoes left in the original position were nonresponding or truly "repelled." Additionally, it remains unclear how to characterize mosquito behavior response to a treatment when they respond by positive anemotaxis into the clean air (control) port. For occasions that we observe this phenomenon, we always follow the test by examining the response to the individual control apparatus with no treatment in the opposite port to test for contamination of either the port or apparatus. ${ }^{46}$

\section{Considerations in the Experimental Design}

In a dual-port olfactometer, there are two common modes by which the device can be operated and this is based on the number of treatments. A noncompetitive assay is arranged so that there is a treatment in one 
port compared to a second port containing the blank control (all apparatus used to hold the treatment, but with the treatment absent). ${ }^{53}$ The advantage of this mode of operation is that it allows a means to compare attraction to treatments based upon a measurement of "inherent" or "absolute" attraction level, without possible interference or complications in mosquito behavior that may arise from interaction with odor released from a treatment in the second port. This approach is commonly used in our laboratory to screen for attractants and inhibitors.

In a competitive assay, one treatment chemical is compared simultaneously to another to provide information on the relative attraction of one treatment to another. ${ }^{53}$ It also can provide information on the interfering effects from an inhibitor released in the opposite port and provide an indication about whether the inhibitor functions best when released at close range to the attractants, or if it can be released from another location and still be effective. The advantage of this technique is that it may provide a closer approximation to field situations where attractants or inhibitors must function in a complex situation against mosquitoes in competition with many other odors. Olfactometers that are used to assess the biological activity of candidate attractants have allowed the development of the human odor blends, ${ }^{68,84-86,101,102,111,136,137}$ such as L-lactic acid and carbon dioxide, ${ }^{138}$ L-lactic acid and ammonia, ${ }^{111}$ L-lactic acid and specific carboxylic acids, ${ }^{86}$ and a three-component blend of L-lactic acid, acetone, and dimethyl disulfide. ${ }^{84,85,102,137}$

The development and use of a standard that has high attraction efficiency, reproducibility, and stability is important when conducting experiments to identify attraction-inhibitors. The use of such a blend has applicability to in vitro repellent experiments by obviating the need for volunteers to participate in in vivo studies. A standard chemical blend of attractants removes the variability inherent in the use of live hosts. Not only do individuals vary in their attractiveness and compound abundances detected, but a single human can vary substantially in both biological activity and compound abundances in their profile from day-to-day. ${ }^{69}$ However, caution must be exercised in the interpretation of results from trials in which blends of attractant chemicals are used because they represent an approximation of a host. These mixtures consist of only a small number of kairomones and it is reasonably certain that of the hundreds of compounds emanated from human skin and some of the important attractants still remain unidentified. Most humans and skin extracts are still more attractive than our best synthetic blends when tested competitively in laboratory bioassays. ${ }^{136,137}$ One of our bioassay protocols for attraction-inhibition involves comparing the response of a standard blend to the response of the same blend, delivered at the same dose but with a candidate attraction-inhibitor added to it. In other cases, the response of the candidate plus another known attractant like L-lactic acid is compared to the response to L-lactic acid alone when looking for synergism. Again, this method of testing attraction-inhibition may be even further removed from reality than using human odors or a more complex blend with higher attractiveness because as noted above, the human odor profile is significantly much more complex.

\section{Correlating Small- and Large-Scale Laboratory Results to Field Experiments}

One concern with results from laboratory bioassays is that they may not correlate well to the performance in the field. Laboratory bioassays are conducted under well-controlled conditions with the temperature, humidity, wind speed, and other variables controlled as needed. Although bioassays can involve movement in space, this movement is often confined. At best, the movement is in essence two dimensional, if not actually closer to a one-dimensional situation in which the mosquito travels linearly upwind through a tube. Additionally, bioassays in the laboratory may only examine a subset of all factors involved in host location, even though this may be intended partly by design. Laboratory olfactometers have a finite length or depth, and thus can best assess only the medium- to close-range stimuli. Finally, bioassays of this nature are considered to be undiscriminating assays in the treatise of Kennedy because the overall result, e.g., attraction, is analyzed as a complex of responses, rather than the individual isolated responses, as would be done in a discriminating assay. ${ }^{21}$ 


\section{Field Tests and Use of Spatial Repellents and Attraction-Inhibitors}

\section{Experimental Design of Field Tests}

\section{Use of Large-Cage Experiments and Laboratory-Reared Colony Mosquitoes}

Researchers have conducted large cage $(9.1 \mathrm{~m}$ wide $\times 18.3 \mathrm{~m}$ long $\times 4.9 \mathrm{~m}$ high, gabled to $5.5 \mathrm{~m})$ studies to simulate environmental conditions that might be encountered in field studies against natural populations of mosquitoes. Traps releasing known attractants at specified release rates are placed in the center of the cage. ${ }^{139} \mathrm{We}$ choose to test with a $2.4 \mathrm{~m} \times 2.4 \mathrm{~m}$ designed perimeter around the trap. A wooden stake with an attached attraction-inhibitor releasing device is located at each corner of the perimeter. An inhibitor release device is attached $0.6 \mathrm{~m}$ above ground level to each stake. Both the inhibitor release device and trap are activated at least $30 \mathrm{~min}$ before mosquitoes were released into the cage, and operated for a specified time period, typically $12 \mathrm{~h}$. At the conclusion of the test period, the trap collection device is retrieved and landing rates on humans are conducted within the cage at several established locations outside the $2.4 \mathrm{~m} \times 2.4 \mathrm{~m}$ perimeter. The landing rate counts are performed in addition to trap collections to provide a more comprehensive indication of the effectiveness of the candidate attraction-inhibitor being tested. The benefits to using a large cage, similar to the benefits of laboratory studies, is that they provide a controlled setting with mosquitoes of known species composition, physiological and chronological age, and quantity. Furthermore, the escape of mosquitoes is minimized. However, the environmental conditions inside the cage are similar to those outside, as is the landscaping within the space. The drawback is that the mosquitoes are not allowed to migrate beyond the enclosure, as they would be able to do in the wild.

\section{Experiments with Wild Mosquitoes in the Field}

One concern with using colony-reared mosquitoes is whether or not they will behave similarly to those in the wild. Additionally, there are a variety of mosquito species and this composition can vary significantly during the course of a study. Conduction of field tests against natural populations of mosquitoes is performed in a similar experimental setup as that used in the large cage studies. A series of $2.4 \mathrm{~m} \times 2.4 \mathrm{~m}$ plots can be established with traps, similarly baited as in the large cages, located in the center with the inhibitor dispensing devices placed on the four corners. A Latin square design can be used with days as replicates. ${ }^{140}$ Initially, treatments and controls should be randomly assigned to each plot. The plots should be located far enough apart to prevent interactions among treatments. The treatments are then moved to new stations each day until all treatments have been evaluated in each plot at least once. Jensen et al. has used a variation of this design to evaluate citronella candles in Illinois. ${ }^{141}$ At each sampling station in their study, the candles were arranged into an equilateral triangle, $3 \mathrm{~m}$ apart, with an individual measuring efficacy sitting in the center, about $1.5 \mathrm{~m}$ from each candle. The individual aspirated mosquitoes trying to bite exposed legs during four 15-min collection periods using a mechanical aspirator.

Another study conducted by Lindsay et al. ${ }^{142}$ in Canada used eight sampling stations arranged in a grid separated by at least $10 \mathrm{~m}$. Two of each kind of dispenser were placed at each sampling period on top of 35-cm-high plastic stands $1 \mathrm{~m}$ apart. A plastic lawn chair was placed between the plastic stands and subjects conducted biting counts while seated on the lawn chairs. The subjects were assigned to one of the eight sampling stations at the beginning of each evening and then rotated through all eight positions twice each night. Treatments were assigned to positions on the grid such that each treatment was at each position during the eight-night evaluation. It is important to evaluate each candidate product under a wide range of field conditions against a diversity of mosquito species, comparing their effectiveness to both negative (untreated) and positive (deet-treated individual) controls. Recently, Webb et al. used carbon dioxide-baited light traps and dispersed candidate inhibitors in a 4 unit $\times 4$ unit grid with each of the 
16 dispensers about $1.5 \mathrm{~m}$ above ground. ${ }^{143}$ Significant repellency was noted for catnip oil, deet, and the E,Z-dihydronepetalactone isomer from catnip oil.

\section{Use of Stand-Alone Inhibitor-Delivery Technology}

Currently, there is a commercial device that is on the market using inhibitor technology based on linalool. The active ingredient is primarily the $(\mathrm{S})-(+)$-linalool isomer [as opposed to $(\mathrm{R})-(-)$-linalool] in candles and sold under the trade name Conceal ${ }^{\circledR}$. However, not all chemicals may be amenable to delivery by candle, and therefore devices similar to another commercial device, the Mosquito Cognito ${ }^{\circledR}$, may be an alternative approach to disperse low levels of inhibitor aerosols into the environment. The active ingredient is contained in cartridges and is used in a battery-powered device.

\section{Potential Applications of Spatial Repellents and Attraction-Inhibitors}

\section{Species-Specific or Species-Exclusive Trapping}

At the present time, not enough is known about the concentration-dependent effects of attractants and attraction-inhibitors and how these chemicals may work or not work on many different mosquito species. Some inhibitors negatively affect the female mosquito at all concentrations tested, and against all species we have tested in the laboratory (Anopheles quadrimaculatus, Anopheles abimanus, Aedes aegypti, Aedes albopictus, and Culex nigripalpus). ${ }^{108}$ The rationale behind species-exclusive trapping would likely involve the use of odors based on avian emanations to selectively lure ornithophilic species of mosquitoes away from opportunistic feeding on a lesser-preferred host, such as humans. There is some basis for exploring this avenue of research because it has been shown that high (and/or low) levels of L-lactic acid are repellent for some species of mosquitoes, ${ }^{78,138,144}$ and that specific species exhibit a strong host-preference based on emanated odors. ${ }^{145}$

\section{Local Area Host-Finding Reduction}

One application of inhibitors has already been discussed in Section "Use of Stand-Alone InhibitorDelivery Technology", i.e., the Mosquito Cognito/Conceal technology. The range of reduction in host finding is $50-95 \%$ with an average of $65 \%$ reduction based on tests in Sarasota, Vero Beach, and Loxahatchee (candles) and Lower Suwannee (candles) wildlife refuges in Florida. ${ }^{146}$ It is possible that additional reduction might be achieved with the discovery of additional attraction-inhibitors. Also, it may be possible to design blends of inhibitors that may function synergistically in their effect, similar to that observed for chemicals used in kairomone blends that are derived from human odorants.

\section{Local Control Using a Push-Pull Strategy with Attractant-Baited Surveillance Traps}

Perhaps one of the greatest benefits to the development of potent inhibitors is the use of these compounds at a slow release rate to conceal host attractive odors in conjunction with surveillance traps to lure and trap or kill as a means of a barrier-forming push-pull strategy. ${ }^{147}$ There are isolated situations, such as was shown in the work of Kline on Atsena Otie Key in Florida, where a reduction in mosquito biting incidence can be obtained using traps with attractants only. ${ }^{148}$ This success is not expected to be possible in an area where competing host odors are constantly present. However, it is believed that even if there is a trap containing an attractant lure that is inferior to host odors, a push-pull strategy may overcome this and allow for local control in small areas.

\footnotetext{
* Registered trademark of BioSensory, Inc., Putnam, CT, USA.
} 


\section{Use of Structure-Activity Relationships to Benefit Development of Attraction-Inhibitors}

Scientists are exploring the use of quantitative structure-activity relationships (QSAR) as a means to examine repellents and to discover the structural basis that results in their biological activity. ${ }^{149,150}$ Furthermore, this approach can be used as a means to predict novel molecular structures that are likely to be repellent. As attraction-inhibition becomes a more precisely characterized phenomenon, with increased numbers of inhibitors, dose response studies, and experiments designed to accurately assess inhibition level, these data should be amenable to QSAR studies. Through QSAR, researchers may also be able to predict the molecular and electronic properties of chemicals that result in attraction-inhibition. A comprehensive understanding of the chemicals could, in time, lead to a better understanding of the function of the odorant receptors. Extensive coverage of approaches to modeling repellents is found in Chapter 10 by Gupta and Bhattacharjee.

\section{References}

1. F. Herbert, October 8, 1920-February 11, 1986.

2. H. H. Shorey, Interaction of insects with their chemical environment, in Chemical Control of Insect Behavior: Theory and Application, H. H. Shorey and J. J. McKelvey (Eds.), New York: Wiley, 1977, pp. $1-5$.

3. P. E. Howse, O. T. Jones, and I. D. R. Stevens, Pheromones and Behavior in Insect Pheromones and their Use in Pest Management, London: Chapman \& Hall, 1998, pp. 3-6.

4. V. G. Dethier, L. Barton Browne, and C. N. Smith, The designation of chemicals in terms of the responses they elicit from insects, J. Econ. Entomol., 53, 134, 1960.

5. P. Karlson and M. Lüscher, "Pheromones": A new term for a class of biologically active substances, Nature, 183, 55, 1959.

6. P. Karlson and M. Lüscher, The proposed term "pheromone", Nature, 183, 1835, 1959.

7. C. I. Bliss, The toxicity of poisons applied jointly, Ann. Appl. Biol., 585, 26, 1939.

8. R. L. Plackett and P. S. Hewlett, Quantal responses to mixtures of poisons, J. Royal. Stat. Soc., 14B, $141,1952$.

9. R. H. Wright, D. L. Chambers, and I. Keiser, Insect attractants, anti-attractants, and repellents, Can. Entomol., 103, 627, 1971.

10. L. B. Browne, Host-related responses and their suppression: Some behavioral considerations, in Chemical Control of Insect Behavior: Theory and Application, H. H. Shorey and J. J. McKelvey (Eds.), New York: Wiley, 1977, pp. 117-127.

11. H. K. Gouck, T. P. McGovern, and M. Beroza, Chemicals tested as space repellents against yellowfever mosquitoes, I. Esters, J. Econ. Entomol., 60, 1587, 1967.

12. J. A. Nolen et al., Method, Apparatus, and Compositions for Inhibiting the Human Scent Tracking Ability of Mosquitoes in Environmentally Defined Three Dimensional spaces, Washington, D.C.: U.S. Patent and Trademark Office, 2002 (U.S. Patent No. 6,362,365).

13. C. E. Schreck and D. L. Kline, Area protection by use of repellent-treated netting against Culicoides biting midges, Mosq. News, 43, 338, 1983.

14. R. A. Wirtz, J. D. Turrentine, Jr., and L. C. Rutledge, Mosquito area repellents: Laboratory testing of candidate materials against Aedes aegypti, Mosq. News, 40, 432, 1980.

15. H. Kawada et al., Field evaluation of spatial repellency of metofluthrin impregnated plastic strips against mosquitoes in Hai Phong City, Vietnam, Am. J. Trop. Med. Hyg., 73, 350, 2005.

16. D. R. Roberts et al., Methods of testing and analyzing excito-repellency responses of malaria vectors to insecticides, J. Am. Mosq. Control Assoc., 13, 13, 1997.

17. K. Ujihara et al., Metofluthrin: A potent new synthetic pyrethroid with high vapor activity against mosquitoes, Biosci. Biotechnol. Biochem., 68, 170, 2004.

18. M. J. Klowden, The physiological control of mosquito host-seeking behavior, in Current Topics in Vector Research, K. F. Harris (Ed.), Vol. 1, Westport, Connecticut: Praeger Scientific, 1983, pp. 93-116. 
19. J. E. Simpson and R. H. Wright, Area treatment to combat mosquitoes, Nature, 214, 113, 1967.

20. W. L. Roelofs and A. Comeau, Sex pheromone perception: Synergists and inhibitors for the red-banded leaf roller attractant, J. Insect Physiol., 17, 435, 1971.

21. J. S. Kennedy, Behaviorally discriminating assays of attractants and repellents, in Chemical Control of Insect Behavior: Theory and Application, H. H. Shorey and J. J. McKelvey (Eds.), New York: Wiley, 1977, pp. 215-229.

22. E. E. Davis, Structure-response relationship of the lactic-acid excited neurons in the antennal groovedpeg sensilla of the mosquito Aedes aegypti, J. Insect Physiol., 34, 443, 1988.

23. S. J. Torr, T. N. C. Mangwiro, and D. R. Hall, Responses of Glossina Pallidipes (Diptera: Glossinidae) to synthetic repellents in the field, Bull. Entomol. Res., 86, 609, 1996.

24. E. B. Dogan and P. A. Rossignol, An olfactometer for discriminating between attraction, inhibition, and repellency in mosquitoes (Diptera: Culicidae), J. Med. Entomol., 36, 788, 1999.

25. E. B. Dogan, J. W. Ayres, and P. A. Rossignol, Behavioural mode of action of deet: Inhibition of lactic acid attraction, Med. Vet. Entomol., 13, 97, 1999.

26. W. A. Skinner et al., Repellency of skin-surface lipids of humans to mosquitoes, Science, 149, 305, 1965.

27. H. I. Maibach et al., Factors that attract and repel mosquitoes in human skin, J. Am. Med. Assoc., 196, $173,1966$.

28. H. I. Maibach et al., Human skin in relationship to mosquito attraction and repulsion, Conn. Med., 33, 23, 1969.

29. W. A. Skinner et al., Human skin-surface lipid fatty acid-Mosquito repellents, Experientia, 26, 728, 1970.

30. S. R. Christophers, Mosquito repellents, Being a report of the work of the mosquito repellent inquiry, Cambridge (1943-5), J. Hygiene., 45, 176, 1947.

31. R. N. McCulloch and D. F. Waterhouse, Laboratory and field tests of mosquito repellents, Bull. Council. Sci. Indust. Res. Aust., 213, 28, 1947.

32. USDA, Report of Work Conducted Under Funds Allotted by the Department of National Defense, Fourth Quarterly Progress Report, Orlando, FL, 1948.

33. T. P. McGovern, M. Beroza, and H. Gouck, Chemicals tested as space repellents against yellow-fever mosquitoes, II. Carbanilates, benzamides, aliphatic amides, and imides, J. Econ. Entomol., 60, 1591, 1967.

34. C. E. Schreck et al., Spatial action of mosquito repellents, J. Econ. Entomol., 63, 1576, 1970.

35. A. A. Khan and H. I. Maibach, A study of insect repellents, 1. Effect on flight and approach by Aedes aegypti, J. Econ. Entomol., 65, 1318, 1972.

36. T. Eisner, Catnip: Its raison d'etre, Science, 146, 1318, 1964.

37. L. R. Garson and M. E. Winnike, Relationships between insect repellency and chemical and physical parameters-A review, J. Med. Entomol., 5, 339, 1968.

38. Peterson, C. J. Insect repellents of natural origin: Catnip and osage orange, Ph.D. dissertation, Iowa State University, Ames, IA, 2001.

39. C. Peterson and J. Coats, Insect repellents—past, present, and future, Pestic. Outlook., 12, 154, 2001.

40. U. R. Bernier et al., Comparison of contact and spatial repellency of catnip oil and $N, N$-diethyl-3methylbenzamide (deet) against mosquitoes, J. Med. Entomol., 42, 306, 2005.

41. K. R. Chauhan et al., Feeding deterrent effects of catnip oil components compared with two synthetic amides against Aedes aegypti, J. Med. Entomol., 42, 643, 2005.

42. J. Boeckh et al., Acylated 1,3-aminopropanols as repellents against bloodsucking arthropods, Pestic. Sci., 48, 359, 1996.

43. E. J. Hoffman and J. R. Miller, Reduction of mosquito (Diptera: Culicidae) attacks on a human subject by combination of wind and vapor-phase deet repellent, J. Med. Entomol., 39, 935, 2002.

44. U. R. Bernier, Unpublished data, 1997.

45. Z. A. Mehr et al., Attraction of mosquitoes to diethyl methylbenzamide and ethyl hexanediol, J. Am. Mosq. Control Assoc., 6, 469, 1990.

46. K. H. Posey, D. R. Barnard, and C. E. Schreck, Triple cage olfactometer for evaluating mosquito (Diptera: Culicidae) attraction responses, J. Med. Entomol., 35, 330, 1998. 
47. E. J. Hoffman and J. R. Miller, Reassessment of the role and utility of wine in suppression of mosquito (Diptera: Culicidae) host finding: Stimulus dilution supported over flight limitation, J. Med. Entomol., 40, 607, 2003.

48. R. R. Painter, Repellents, in Pest Control: Biological, Physical and Selected Chemical Methods, W. W. Kilgore and R. R. Painter (Eds.), New York: Academic Press, 1967.

49. G. F. Shambaugh, R. F. Brown, and J. J. Pratt, Jr., Repellents for biting arthropods, in Advances in Pest Control Research, Vol. 1, R. L. Metcalf (Ed.), New York: Interscience Publishers, 1957, pp. 277-303.

50. K. Narusuye et al., Linalool suppresses voltage-gated currents in sensory neurons and cerebellar purkinje cells, J. Neural Trans., 112, 193, 2005.

51. M. A. Birkett et al., The role of volatile semiochemicals in mediating host location and selection by nuisance and disease-transmitting cattle flies, Med. Vet. Entomol., 18, 313, 2004.

52. R. H. Bedoukian, Method and Compositions for Inhibiting the Scent Tracking Ability of Mosquitoes and Biting Midges, Washington D.C.: U.S. Patent and Trademark Office, 2005. Published U.S. Patent Application No. 20050090563.

53. D. L. Kline et al., Olfactometric evaluation of spatial repellents for Aedes aegypti, J. Med. Entomol., 40, 463, 2003.

54. M. Markowitz, Practical Survey of Chemistry and Metabolism of the Skin, Philadelphia: Blakiston Company, 1942.

55. H. C. Koring et al., Changes in skin $\mathrm{pH}$ and resident flora by washing and synthetic detergent preparations at pH 5.5 and 8.5, J. Soc. Cosmet. Chem., 42, 147, 1991.

56. N. Nicolaides, H. C. Fu, and G. R. Rice, The skin surface lipids of man compared with those of eighteen species of animals, J. Invest. Dermatol., 51, 83, 1968.

57. N. Nicolaides, H. C. Fu, and M. N. A. Ansari, Diester waxes in surface lipids of animal skin, Lipids, 5, 299-307, 1970.

58. N. Nicolaides et al., Lipid composition of comedomes compared with that of human skin surface in acne patients, J. Invest. Dermatol., 54, 487, 1970.

59. M. N. A. Ansari, N. Nicolaides, and H. C. Fu, Fatty acid composition of the living layer and stratum corneum lipids of human sole skin epidermis, Lipids, 5, 838, 1970.

60. S. D. Sastry et al., Volatiles emitted by humans, in Biochemical Applications of Mass Spectrometery, First Supplementary Volume, G. R. Waller and O. C. Dermer et al. (Eds.), Chichester: Wiley, 1980, pp. 1085-1129.

61. R. I. Ellin et al., An apparatus for the detection and quantitation of volatile human effluents, J. Chromatogr., 100, 137, 1974.

62. K. Naitoh et al., New measurement of hydrogen gas and acetone vapor in gases emanating from human skin, Instr. Sci. Technol., 30, 267, 2002.

63. Y. Shirai et al., Alcohol ingestion stimulates mosquito attraction, J. Am. Mosq. Control Assoc., 18, 91, 2002.

64. U. R. Bernier, M. M. Booth, and R. A. Yost, Analysis of human skin emanations by gas chromatography/mass spectrometry, 1. Thermal desorption of attractants for the yellow fever mosquito (Aedes aegypti) from handled glass beads, Anal. Chem., 71, 1, 1999.

65. X.-N. Zeng et al., Analysis of characteristic odors from human male axillae, J. Chem. Ecol., 17, 1469, 1991.

66. X.-N. Zeng et al., An investigation of human apocrine gland secretion for axillary odor precursors, J. Chem. Ecol., 18, 1039, 1992.

67. U. R. Bernier et al., Analysis of human skin emanations by gas chromatography/mass spectrometry, 2. Identification of volatile compounds that are candidate attractants for the yellow fever mosquito (Aedes aegypti), Anal. Chem., 72, 747, 2000.

68. U. R. Bernier et al., Chemical analysis of human skin emantions: Comparison of volatiles from humans that differ in attraction of Aedes aegypti (Diptera: Culicidae), J. Am. Mosq. Control Assoc., 18, 186, 2002.

69. C. E. Schreck, D. L. Kline, and D. A. Carlson, Mosquito attraction to substances from the skin of different humans, J. Am. Mosq. Control Assoc., 6, 406, 1990. 
70. K. G. Asano et al., Chemical composition of fingerprints for gender determination, J. Forensic Sci., 47, 805, 2002.

71. A. M. Curran, S. I. Rabin, and K. G. Furton, Analysis of the uniqueness and persistence of human scent, Forensic Sci. Commun., 72, 1, 2005.

72. A. M. Curran et al., Comparison of the volatile organic compounds present in human odor using spme-gc/ms, J. Chem. Ecol., 31, 1607, 2005.

73. W. Ma and W. R. Klemm, Determination of acetaldehyde in blood by solid phase extraction and high performance liquid chromatography, Alcohol, 14, 469, 1997.

74. R. Andreoli et al., Determination of patterns of biologically relevant aldehydes in exhaled breath condensate of healthy subjects by liquid chromatography/atmospheric chemical ionization tandem mass spectrometry, Rapid Commun. Mass Spectrom., 17, 637, 2003.

75. B. Krotoszynski, G. Gabriel, and H. O'Neill, Characterization of human expired air: A promising investigative and diagnostic technique, J. Chromatogr. Sci., 15, 239-244, 1977.

76. M. Phillips, Method for the collection and assay of volatile organic compounds in breath, Anal. Biochem., 247, 272, 1997.

77. D. L. Ashley et al., Determining volatile organic compounds in human blood from a large sample population by using purge and trap gas chromatography/mass spectrometry, Anal. Chem., 64, 1021, 1992.

78. W. Rudolfs, Chemotropism of mosquitoes, Bull. N.J. Agric. Exp. Sta., 367, 4, 1922.

79. M. Bar-Zeev, H. I. Maibach, and A. A. Khan, Studies on the attraction of Aedes aegypti (Diptera: Culicidae) to man, J. Med. Entomol., 14, 113, 1977.

80. M. T. Gillies, The role of carbon dioxide in host-finding by mosquitoes (Diptera: Culicidae): A review, Bull. Ent. Res., 70, 525, 1980.

81. W. Takken, The role of olfaction in host-seeking of mosquitoes: A review, Insect Sci. Applic., 12, 287, 1991.

82. T. Dekker, M. Geier, and R. T. Cardé, Carbon dioxide instantly sensitizes female yellow fever mosquitoes to human skin odors, J. Exp. Biol., 208, 2963, 2005.

83. W. R. Mukabana et al., Allomonal effect of breath contributes to differential attractiveness of humans to the African malaria vector Anopheles gambiae, Malar. J., 3, 1, 2004. (http://www. malariajournal.com/content/3/1/1).

84. U. R. Bernier et al., Chemical Composition that Attract Arthropods, Washington D.C.: U.S. Patent and Trademark Office, 2001, U.S. Patent No. 6,267,953.

85. U. R. Bernier et al., Chemical Composition that Attract Arthropods, Washington D.C.: U.S. Patent and Trademark Office, 2004, U.S. Patent No. 6,800,279.

86. O. J. Bosch, M. Geier, and J. Boeckh, Contribution of fatty acids to olfactory host finding of female Aedes aegypti, Chem. Senses., 25, 323, 2000.

87. R. C. Smallegange et al., Synergism between ammonia, lactic acid and carboxylic acids as kairomones in the host-seeking behavior of the malaria mosquito Anopheles gambiae sensu stricto (Diptera: Culicidae), Chem. Senses., 30, 145, 2005.

88. C. Constantini et al., Electroantennogram and behavioral response of the malaria vector Anopheles gambiae to human-specific sweat components, Med. Vet. Entomol., 15, 259, 2001.

89. W. G. Reifenrath, Natural Insect Repellant, Washington D.C.: U.S. Patent and Trademark Office, 2005, U.S. Patent No. 6,953,814.

90. H. D. Douglas III, et al., Heteropteran chemical repellents identified in the citrus odor of a seabird (crested auklet: Aethia cristatella): Evolutionary convergence in chemical ecology, Naturwissenschaften, 88, 330, 2001.

91. H. D. Douglas III, et al., Interspecific differences in Aethia spp. auklet odorants and evidence for chemical defense against ectoparasites, J. Chem. Ecol., 30, 1921, 2001.

92. H. D. Douglas III, et al., Chemical odorant of colonial seabird repels mosquitoes, J. Med. Entomol., 42, 647, 2005.

93. J. C. Hagelin, I. L. Jones, and L.E L. Rasmussen, A tangerine-scented social odour in a monogamous seabird, Proc. R. Soc. Lond., 270B, 1323, 2003. 
94. P. Steullet and P. M. Guerin, Identification of vertebrate volatiles stimulating olfactory receptors on tarsus I of the tick Amblyomma Variegatum Fabricus (Ixodidae), J. Comp. Physiol., 174A, 27, 1994.

95. P. G. Guerenstein and P. M. Guerin, Olfactory responses of the blood-sucking bug Triatoma infestans to odours of vertebrate hosts, J. Exp. Biol., 204, 585, 2001.

96. V. G. Dethier, Olfactory responses of blowflies to aliphatic aldehydes, J. Gen. Physiol., 37, 743, 1954.

97. S. Haze et al., 2-Nonenal newly found in human body odor tends to increase with aging, J. Invest. Dermatol., 116, 520, 2001.

98. Z.-M. Zhang et al., The study of fingerprint characteristics of the emanations from human arm skin using the original sampling system by spme-gc/ms, J. Chromatogr., 822B, 244, 2005.

99. Y. K. Takahashi, S. Nagayama, and K. Mori, Detection of spoiled food smells by odor maps in the olfactory bulb, J. Neurosci., 24, 8690, 2004.

100. M. Corradi et al., Aldehydes in exhaled breath condensate of patients with chronic obstructive pulmonary disease, Am. J. Respir. Crit. Care Med., 167, 1380, 2003.

101. U. R. Bernier et al., Unpublished data, 2005.

102. U. R. Bernier et al., Synergistic attraction of Aedes aegypti (L.) to binary blends of L-lactic acid and acetone, dichloromethane, or dimethyl disulfide, J. Med. Entomol., 40, 653, 2003.

103. A. W. Ralston and J. P. Barrett, Insect Repellent Containing Aliphatic Alcohols, Washington D.C.: U.S. Patent and Trademark Office, 1941, U.S. Patent No. 2,254,665.

104. B. G. Wilkes, Insect Repellents, Washington D.C.: U.S. Patent and Trademark Office, 1946, U.S. Patent No. 2,407,225.

105. P. Granett and H. L. Haynes, Insect-repellent properties of 2-ethylhexanediol-1,3, J. Econ. Entomol., 38, 671, 1945.

106. D. R. Hall et al., 1-Octen-3-ol: A potent olfactory stimulant and attractant for tsetse isolated from cattle odors, Insect Sci. Applic., 7, 5, 1984.

107. W. Takken and D. L. Kline, Carbon dioxide and 1-octen-3-ol as mosquito attractants, J. Amer. Mosq. Control Assoc., 5, 311, 1989.

108. U. R. Bernier, Unpublished data, 2000.

109. J. P. Conkle et al., Detailed study of contaminant production in a space cabin simulator at $760 \mathrm{~mm}$ of mercury, Aerospace Med., 38, 491, 1967.

110. P. A. Wright, Nitrogen excretion: Three end products, many physiological roles, J. Exper. Biol., 198, 273, 1995.

111. M. Geier, O. J. Bosch, and J. Boeckh, Ammonia as an attractive component of host odour for the yellow fever mosquito, Aedes aegypti, Chem. Senses., 24, 647, 1999.

112. M. A. H. Braks, J. Meijerink, and W. Takken, The response of the malaria mosquito, Anopheles gambiae, to two components of human sweat, ammonia and L-lactic acid, in an olfactometer, Physiol. Entomol., 26, 142, 2001.

113. U. R. Bernier, Unpublished data, 1999.

114. C. W. O. Bunker and A. D. Hirshfelder, Mosquito repellents, Am. J. Trop. Med., 5, 359, 1925.

115. L. A. O. Roadhouse, Laboratory studies on insect repellency, Can. J. Zool., 31, 535, 1953.

116. V. G. Dethier, Repellents, Ann. Rev. Entomol., 1, 181, 1956.

117. A. Cork and K. C. Park, Identification of electrophysiologically-active compounds for the malaria mosquito, Anopheles gambiae, in human sweat extracts, Med. Vet. Entomol., 10, 269, 1996.

118. A. Ostrovskaya et al., Study and identification of volatile compounds from human skin, J. Cosmetic Sci., 53, 147, 2002.

119. F. Kanda et al., Elucidation of chemical compounds responsible for foot malodour, Brit. J. Dermatol., 122, 771, 1990.

120. E. D. Adrian, The activity of the nervous system in the caterpillar, J. Physiol., 70, 34, 1930.

121. W. Roelofs et al., Sex attractant of the colding moth: Characterization with electroantennogram technique, Science, 174, 291, 1971. 
122. W. C. Agosta, Chemical Communication: The Language of Pheromones, Scientific American Library, New York: W.H. Freeman \& Co., 1992, p. 66.

123. A. Cork et al., Gas chromatography linked to electroantennography: A versatile technique for identifying insect semiochemicals, in Chromatography and Isolation of Insect Hormones and Pheromones, A. R. McCaffery, D. Wilson et al. (Eds.), London: Plenum Press, 1990.

124. A. Cork, Olfactory basis of host-finding in haemotophagous arthropods, in Olfaction in Mosquito-Host Interactions, Ciba Foundation Symposium No. 200, G. R. Cardew (Ed.), London: John Wiley \& Sons, 1996.

125. J. Meijerink et al., Identification of olfactory stimulants for Anopheles gambiae from human sweat samples, J. Chem. Ecol., 26, 1367, 2000.

126. Y. T. Qiu et al., Behavioural and electrophysiological responses of the malaria mosquito Anopheles gambiae Giles sensu stricto (Diptera: Culicidae) to human skin emanations, Med. Vet. Entomol., 18, 429, 2004.

127. E. Bursell et al., Identification of compounds of cattle urine attractive to tsetse flies. Glossina spp. (Diptera: Glossinidae), Bull. Entomol. Res., 78, 281, 1988.

128. A. Cork, Identification of electrophyisologically-active compounds for new world screwworm, Cochliomyia hominovorax, in larval wound fluid, Med. Vet. Entomol., 8, 151, 1994.

129. W. M. Hoskins and R. Craig, The olfactory responses of flies in a new type of insect olfactometer, I. Theory and design of the olfactometer, J. Econ. Entomol., 27, 1029, 1934.

130. J. O. G. Wieting and W. M. Hoskins, The olfactory responses of flies in a new type of insect olfactometer, II. Responses of the housefly to ammonia, carbon dioxide and ethyl alcohol, J. Econ. Entomol., 32, 24, 1939.

131. E. R. Willis, The olfactory responses of female mosquitoes, J. Econ. Entomol., 40, 769, 1947.

132. H. K. Gouck and C. E. Schreck, An olfactometer for use in the study of mosquito attractants, J. Econ. Entomol., 58, 589, 1965.

133. C. E. Schreck, H. K. Gouck, and N. Smith, An improved olfactometer for use in studying mosquito attractants and repellents, J. Econ. Entomol., 60, 1188, 1967.

134. J. P. Grieco et al., A novel high-throughput screening system to evaluate the behavioral response of adult mosquitoes to chemicals, J. Am. Mosq. Control Assoc., 21, 404, 2005.

135. W. M. Barrows, The reactions of the pomace fly, Drosophila ampelophila Loew, to odorous substances, J. Exper. Zool., 4, 515, 1907.

136. M. Geier, H. Sass, and J. Boeckh, A search for components in human body odour that attract females of Aedes aegypti, in Olfaction in Mosquito-Host Interactions, Ciba Foundation Symposium No. 200, G. R. Cardew (Ed.), London: John Wiley \& Sons, 1996.

137. U. R. Bernier et al., Laboratory comparison of Aedes aegypti (L.) attraction to human odors and to synthetic human odor compounds and blends, J. Am. Mosq. Control Assoc., in press.

138. C. N. Smith et al., L-lactic acid as a factor in the attraction of Aedes aegypti (Diptera Culicidae) to human hosts, Ann. Entomol. Soc. Am., 63, 760, 1970.

139. D. L. Kline, Unpublished data, 2000.

140. W. G. Cochran and G. M. Cox, Experimental Design, New York: Wiley, 1957.

141. T. Jensen et al., Field efficacy of commercial antimosquito products in Illinois, J. Am. Mosq. Control Assoc., 16, 148, 2000.

142. L. R. Lindsay et al., Evaluation of the efficacy of $3 \%$ citronella candles and $5 \%$ citronella incense for protection against field populations of Aedes mosquitoes, J. Am. Mosq. Control Assoc., 12, 293, 1996.

143. R. E. Webb et al., Evaluation of spatial repellents against mosquitoes in the field, J. Am. Mosq. Control Assoc., in press.

144. Y. Shirai et al., L-lactic acid as a mosquito (Diptera: Culicidae) repellent on human and mouse skin, J. Med. Entomol., 38, 51, 2001.

145. S. A. Allan, U. R. Bernier, and D. L. Kline, Laboratory evaluation of avian odors for mosquito (Diptera: Culicidae) attraction, J. Med. Entomol., in press.

146. J. A. Nolen, Personal communication, 2006. 
147. J. R. Miller and R. S. Cowles, Stimulo-deterrent diversion: A concept and its possible application to onion maggot control, J. Chem. Ecol., 16, 3197, 1990.

148. D. L. Kline, Unpublished data, 2005.

149. C. Hansch, A. Leo, and D. H. Hoekman, Exploring QSAR., ACS Professional Reference Book, Washington D.C.: American Chemical Society, 1995.

150. D. Ma et al., Predicting mosquito repellent potency of $N, N$-diethyl- $m$-toluamide (deet) analogs from molecular electronic properties, Am. J. Trop. Med. Hygiene., 60, 1, 1999. 